\title{
Compensações financeiras obtidas por fornecedores de componentes premium em transações industriais
}

\author{
Financial compensations achieved by premium item \\ suppliers in business-to-business transactions
}

\author{
Fábio Rovian Pereira Benevite ${ }^{1}$ \\ Giancarlo Medeiros Pereira ${ }^{1}$ \\ Miguel Afonso Sellitto ${ }^{1}$ \\ Miriam Borchardt ${ }^{1}$
}

\begin{abstract}
Resumo: Este artigo investiga as compensações financeiras obtidas por fornecedores de componentes industriais de itens classificados como premium (produtos de alto valor agregado) ao atenderem às principais demandas de valor dos grandes compradores industriais. As compensações financeiras incluem aumento no preço e na fração do lote de compra (percentual do lote de compra destinado a cada fornecedor). O método de pesquisa foi o estudo de caso múltiplo. A pesquisa envolveu, de um lado, cinco clientes globais oriundos dos setores de siderurgia, bebidas e equipamentos, e de outro quatro fornecedores de componentes industriais: rolamentos especiais, subsistemas hidráulicos, subsistemas pneumáticos e equipamentos eletrônicos. A pesquisa investigou valores descritos na literatura para suprimentos industriais (produto, serviço e suprimento) e identificou que o valor produto é prioritário e os valores suprimento e serviços usualmente são considerados após a aprovação técnica do valor produto. A pesquisa também quantifica a influência da combinação desses valores em níveis de preços e fração do lote de compra. Os resultados auferidos sugerem questões para futuras pesquisas, as quais serão organizadas em forma de survey.
\end{abstract}

Palavras-chave: Valores. Gestão de suprimentos. Gestão de serviços. Par produto - serviço.

\begin{abstract}
This paper investigates financial compensations achieved by premium item suppliers when they meet the value demands from industry clients. Financial compensations include an increase in the values and share of orders. The research methodology used was the multiple case study. This study included five global clients from the steelmaking, beverage, and equipment industry sectors and four suppliers of premium industrial components (Industrial bearings, Hydraulics, Pneumatic subsystems, and Electronics). The following value drivers were found in the literature: product, service, and supply. Determining the value of the product is a priority followed by supply and service whose values are usually determined after the product is technically approved. This study also quantified the influence of the combination of these values, or prices, and those of the share of orders. Questions for further research, i.e. surveys, were suggested.
\end{abstract}

Keywords: Value management. Supply management. Service management. Product-service pack.

\section{Introdução}

A questão dos valores demandados por compradores industriais de itens premium (alto valor agregado) tem sido objeto de estudo de pesquisadores. Até quanto se pesquisou, os resultados destes trabalhos têm apontado para três valores principais: (i) produto (MATTHYSSENS; VANDENBEMPT; BERGHMAN, 2006; LINDGREEN; WYNSTRA, 2005); (ii) serviço (ULAGA; EGGERT, 2006; VARGO; LUSCH, 2004; JACKSON; NEIDELL; LUNSFORD; BANTING, 1984; ANDREASEN; BEST, 1977); e (iii) suprimento (HSIEH; CHIU; HSU, 2008; CHAKRABORTY; SRIVASTAVA; MARSHALL, 2007; CANNON;
HOMBURG, 2001; NOORDEWIER; JOHN ; NEVIN, 1990). Valor de produto para o comprador ocorre quando um item ou subsistema atende às demandas de desempenho operacional; valor de serviço está ligado à necessidade de atividades paralelas à fabricação e uso do produto, tais como treinamento e assistência técnica; e valor de suprimento está ligado à garantia de continuidade e de confiabilidade de entregas.

Pesquisaram-se artigos publicados em periódicos como o Supply Chain Management: An International Journal; International Journal of Operations and Production Management; International Journal of

\footnotetext{
Programa de Pós-Graduação em Engenharia de Produção e Sistemas - PPGEPS, Universidade do Vale do Rio dos Sinos - UNISINOS, Av. Unisinos 950, Bloco 5A, CEP 93022-000, São Leopoldo - RS, Brasil, E-mails: gian@ unisinos.br; benevitefabio@gmail.com; sellitto@unisinos.br; miriamb@unisinos.br
} 
Purchasing and Supply Chain Management; Industrial Marketing Management e Journal of Business and Industrial Marketing, entre os anos 1966 e 2008. Nestes veículos e neste intervalo de tempo, não foi encontrada pesquisa que visasse a determinar a influência desses valores nos níveis de preço e na fração da ordem de compra (percentual do lote de compra destinado a cada fornecedor) junto aos grandes compradores industriais. Cumpre destacar que os três elementos descritos podem influenciar a lucratividade das organizações, quer compradoras (via redução dos custos logísticos totais), quer vendedoras (via ampliação dos preços e da margem de lucro).

$\mathrm{O}$ conceito de valor se refere à diferença entre os benefícios percebidos pelo cliente e os custos com que arca para tê-los. Desta forma, custos de mudança, instalação, suporte técnico e manutenção são alguns dos elementos que influenciam a percepção de valor por parte dos clientes industriais (KHALIFA, 2004; LINDGREEN; WYNSTRA, 2005; PAYNE; HOLT, 2001; ULAGA, 2001). Em abordagem similar, Matthyssens e Vandenbempt (2008) postulam que, para clientes, valor é usualmente relacionado ao valor percebido por estes. Assim sendo, as empresas precisam permanentemente reinventar o modo como seus clientes percebem os produtos ou serviços adquiridos (KHALIFA, 2004; PAYNE; HOLT, 2001; ULAGA, 2001).

Com efeito, a criação do valor é opção à disposição das empresas para reverter a tendência de perda de diferenciais ao longo do tempo, perda essa que resulta em redução do lucro passível de ser auferido por elas. A tendência descrita se torna mais intensa a partir do momento em que os grandes compradores se profissionalizam, ou quando os produtos são de difícil diferenciação (MATTHYSSENS; VANDENBEMPT, 2008).

O objetivo de fundo deste artigo é ampliar o entendimento acerca dos valores demandados por compradores industriais e as possíveis compensações financeiras que fornecedores possam auferir por oferecer tais valores. O objetivo principal de pesquisa foi descobrir o que pode esperar um fornecedor de item premium como compensação financeira por fugir à lógica de livre-mercado e assim oferecer valores efetivamente demandados por clientes. Os objetivos secundários foram: (i) descobrir como se compõe a compensação financeira de fornecedores premium; (ii) descobrir o que oferecer para obtê-la; e (iii) descobrir até quanto ela pode ir. A questão de pesquisa foi: como ocorre a compensação financeira de um fornecedor de itens de alto valor agregado que atende às demandas de valor dos grandes clientes industriais? O método de pesquisa foi o estudo de caso múltiplo. Tal estratégia é adequada a questões do tipo como (YIN, 1994). Investigou-se a influência dos três valores citados em um grupo de componentes industriais de alto valor agregado (rolamentos, sistemas hidráulicos, componentes pneumáticos e componentes eletrônicos). As empresas investigadas (compradoras e vendedoras) conduzem operações globais. As empresas compradoras atuam nas áreas de siderurgia, mineração, fabricação de equipamentos e de bebidas. Este método é apontado por Eisenhardt (1989) como capaz de, por repetição e aprendizagem, gerar elementos suficientes para a construção de uma teoria fundamentada (grounded theory) sobre o objeto de estudo. As questões originadas na pesquisa serão investigadas em um futuro survey.

Por fim, porém não menos importante, cumpre aqui destacar que este estudo não tenciona definir valores numéricos para a valoração dos elementos investigados, mesmo por que o método utilizado não o permite. Com o efeito, este estudo se propõe a desvelar novas linhas de investigação científica em nível de projeto de produtos, gerenciamento logístico e gestão de serviços industriais.

O restante do artigo está organizado do seguinte modo: revisão teórica, metodologia, análise das informações coletadas, discussão e conclusões. Ao final, são apresentadas algumas sugestões para futuros estudos, bem como apresentadas as limitações do presente trabalho.

\section{Geradores de valor e compensações financeiras}

Para o objetivo deste artigo, a expressão "compensação financeira" define o adicional de preço que os clientes industriais estariam dispostos a pagar a fornecedores que garantam os valores demandados por eles. Apesar da importância das pesquisas descritas na literatura revisada, nenhum estudo foi encontrado focalizando os limites de compensação financeira possíveis de serem alcançados por vendedores. A compensação financeira aceita por um cliente em troca de um dado valor provido por seus fornecedores pode redundar em custos desnecessários, quando não reflete o justo montante aceito pelo mercado para o respectivo valor.

Os efeitos positivos dos valores agregados por transações empresariais sobre a lealdade dos consumidores foram descritos por autores, tais como Bolton e Drew (1991), Fornell (1992), Rust e Zahorik (1993), Scheuing (1995), Reichheld (1996), e Eriksson e Löfmarck-Vaghult (2000). Outra linha de estudos investigou o relacionamento entre serviços e qualidade de produtos e lucratividade da operação (CHUSIL; DOWNS, 1979; BUZZELL; GALE, 1987). Evidências acerca da influência dos serviços na lucratividade de operações também foram apresentadas por Zeithaml (2000). Hinterhuber (2004) postula que o entendimento do valor demandado pelos clientes industriais e sua tradução em preços de venda efetivamente aceitos por eles permitem à organização vendedora ampliar o resultado financeiro auferido com a venda de produtos. 
Wouters, Anderson e Wynstra (2005) postulam que, do ponto de vista dos compradores, qualquer decisão de compra deveria estar associada ao conceito de custo total de aquisição. Segundo esse conceito, todos os custos adicionais que surgem no escopo da transação deveriam ser considerados na definição de uma opção de compras industrial. Dentre esses, citem-se os custos de aquisição (por exemplo: emissão de pedido, frete e controle de qualidade); de manutenção de estoques (por exemplo: custo de capital, armazenagem, manuseio, seguros e obsolescência); de procedimentos de garantia de qualidade dos itens adquiridos (por exemplo: refugos, retrabalhos, paradas na linha e garantias); e de atendimento a problemas de suprimento (CARR; ITTNER, 1992; ELLRAM, 1995).

Apesar da importância da redução dos custos logísticos para a competitividade empresarial, até quanto se pesquisou, a literatura consultada não apresentou nenhum estudo focado na quantificação da compensação financeira usualmente praticada pelos grandes compradores globais. Em um dos poucos estudos encontrados na revisão da literatura que se focaram na combinação entre compensação financeira e valor agregado, Anderson, Thomson e Wynstra (2000) identificaram que os gestores de compra não relacionam linearmente valores ofertados e preços, informação essa que suscita reflexões acerca das ações que podem ser orquestradas tanto em nível de vendedores (ampliação da compensação financeira) quando de compradores (redução dos custos de aquisição). No que se refere à compensação em volume, Hinterhuber (2004) afirma que muitos gestores hesitam em associar a conquista de grandes fatias de mercado a produtos de maior valor agregado (tipo premium) e, portanto, de maior preço. Segundo o autor, é consenso que preços superiores somente podem ser praticados em mercados altamente específicos. $\mathrm{O}$ autor sustenta ainda que a associação entre preços maiores e a conquista de uma parcela mais significativa do mercado somente pode ser viabilizada em situações em que o cliente efetivamente perceba os diferenciais que são agregados pelo conjunto produto - serviço oferecido pelo fornecedor.

Analisando-se o exposto, e considerando que o volume de pedidos destinado a um fornecedor pode ser uma forma de compensação a fornecedores, cumpre aqui questionar: Qual fatia do total de pedidos de um dado componente é usualmente direcionada aos melhores fornecedores de produtos premium? A literatura consultada não apresentou respostas a tal questão.

Todavia, também é preciso considerar que a percepção de valor varia entre clientes (BENNION; REDMOND, 1994; GIUNIPERO; BREWER, 1993; OLIVER, 1997). Com isto, as empresas devem permanentemente desenvolver produtos e serviços que atendam às demandas específicas dos clientes, geralmente relacionadas à performance e aos aspectos logísticos, mercadológicos ou financeiros (KENT; MENTZER, 2003; CANNON; HOMBURG, 2001). A análise das referências listadas não menciona a existência de qualquer hierarquia entre os valores mais desejados pelos compradores industriais quando da definição de uma dada opção de fornecimento, especialmente em produtos do tipo premium. Assim sendo, pode-se estabelecer a seguinte proposição:

P1 As empresas compradoras não seguem uma hierarquia comum de valores quando da seleção de seus fornecedores de produtos premium.

Os próximos tópicos se concentraram na análise dos valores que influenciam a opção por um dado fornecedor: produto, serviço e suprimento.

\subsection{Geração de valor por produto}

Matthyssens, Vandenbempt e Berghman (2006) concluíram que a diferenciação apoiada na inovação técnica e na qualidade dos produtos é importante gerador de valor para clientes industriais. Contudo, os critérios de avaliação de produtos também podem variar conforme o componente a ser adquirido, ou seja, componentes para a manutenção podem não ser tratados da mesma forma que componentes a serem inseridos no produto final da compradora (LINDGREEN; WYNSTRA, 2005). Apesar da importância de ampliar o entendimento desses elementos em níveis de suprimentos e de marketing industrial, nenhum estudo científico focado na influência dos valores afetos ao produto em termos de preço e fração de pedido de um dado componente foi encontrado na literatura pesquisada.

Baseado no referencial apresentado é possível formular a seguinte proposição:

P2 A oferta de produtos com características técnicas diferenciadas permite aos fornecedores praticar preços superiores aos de produtos com especificação similar, mas sem tal desempenho, assim como auferir a maior fatia do total de ordens de compra emitidas para um componente.

\subsection{Geração de valor por serviços}

Ulaga e Eggert (2006) demonstraram que elementos como preço e valores associados ao produto (especificações técnicas), embora importantes, são menos atrativos na definição de compra por uma grande empresa. Segundo os autores, o serviço de suporte, a interação entre fornecedor e cliente e o fornecimento de conhecimento técnico são os diferenciais mais demandados atualmente pelos compradores industriais. Vargo e Lusch (2004), por sua vez, enfatizam que os clientes fazem avaliações críticas de um dado produto em uso baseados, principalmente, no nível de serviços providos pelo fornecedor. Dentre esses 
serviços, citem-se a manutenção, o reparo e os serviços operacionais, financeiros e de suporte antes e após a entrega do produto (JACKSON; NEIDELL; LUNSFORD, 1995).

Gebauer e Friedli (2005) postulam que as empresas de manufatura devem concentrar-se na oferta de serviços diferenciados para alavancar suas operações de venda. Os autores salientam que os serviços permitem ao fornecedor de produtos ampliar sua margem de ganhos, ao mesmo tempo em que constroem barreiras não relacionadas a preços para seus concorrentes.

Todavia, Matthyssens e Vandenbempt (2008), Anderson e Narus (2004) e Baden-Fuller e Stopford (1994) identificaram que as empresas de manufatura têm encontrado dificuldades para prover serviços que efetivamente agreguem valor para seus clientes. Segundo os autores, muitas ofertas realizadas pelos fornecedores têm gerado resultados financeiros aquém do esperado, especialmente no mercado de alto valor agregado. Essa conclusão parece sugerir que os ambientes acadêmicos e empresariais carecem de um melhor entendimento acerca dos elementos que influenciam positivamente a agregação de valor na venda de serviços associada a produtos industriais. Com efeito, a maioria dos estudos da área tem focado quase que exclusivamente os serviços para o consumidor final, contexto esse bastante diferente daquele que surge quando se estabelece uma relação comercial entre organizações de porte semelhante.

Inobstante aos desafios descritos, as empresas de manufatura permanecem incrementando sua oferta de serviços (WINDAHL; LAKEMOND, 2006). As abordagens verificadas se concentram na busca pela mudança do tradicional foco de "funcionalidade do produto" para "resultados que o par produto mais serviços" é capaz de trazer para o cliente industrial (DAVIES, 2003). Essa nova estratégia desafia alguns pressupostos antigos até então vigentes na venda de produtos, de peças de reposição e de assistência técnica (WINDAHL; LAKEMOND, 2006), assim como suscita questionamentos acerca do mix de serviços a ser oferecido aos clientes (OLIVA; KALLENBERG, 2003).

Uma análise das referências apresentadas permite identificar que não mencionam nenhuma ligação entre o tipo de serviço requerido pelo cliente e o retorno auferido por seu provedor em termos de preço ou fração do lote de compra. Baseado nessa conclusão é possível enunciar a seguinte proposição:

P3 A capacidade de prover os serviços demandados pelo cliente industrial de produtos manufaturados permite aos fornecedores praticar preços superiores aos de produtos com especificação similar, mas sem tal desempenho. Os serviços também permitem ao fornecedor auferir a maior fatia do total de ordens de compra emitidas para um componente.

\subsection{Geração de valor por confiabilidade de suprimento}

Outro agregador de valor em compras industriais é a confiabilidade que o fornecedor possa atribuir ao suprimento. Conforme Paiva, Carvalho e Fensterseifer (2004), confiabilidade de suprimento é a probabilidade de, dado que uma demanda foi feita, esta seja atendida na integralidade no prazo estabelecido normalmente entre as partes. Alguns autores, tais como Ballou (2006), relacionam a confiabilidade do suprimento ao nível de serviço ao cliente em operações de distribuição.

Chakraborty, Srivastava e Marshall (2007) identificaram que a confiabilidade de suprimento é a mais importante dimensão de valor demandada pelos clientes industriais de itens hidráulicos e pneumáticos. Hsieh, Chiu e Hsu (2008), por seu turno, postulam que a confiabilidade de suprimento agrega significativo valor aos clientes empresariais que demandam flexibilidade, pois esta pode ser considerada uma característica do suprimento confiável. Cannon e Homburg (2001) e Noordewier, John e Nevin (1990) definem flexibilidade como a capacidade do fornecedor em atender a demandas inesperadas de clientes, o que se traduz em importante diferencial de mercado (MATTHYSSENS; VANDENBEMPT; BERGHMAN, 2006).

A despeito da importância do valor "suprimento confiável", a presente revisão da teoria não identificou nenhuma menção aos limites que possui em termos de preços e fração de pedidos. A viabilização de um maior entendimento acerca desses elementos permitirá que os fornecedores possuam bases mais confiáveis para avaliar mudanças em seus sistemas logísticos. Ademais, o referido conhecimento igualmente permitirá que os clientes avaliem suas políticas de abastecimento com vistas à oferta de compensações (financeiras ou de volume) que sejam atrativas aos seus fornecedores.

Isso posto, pode-se então enunciar uma nova proposição, a saber:

P4 O suprimento confiável permite aos fornecedores praticar preços superiores aos de produtos com especificação similar, mas sem tal desempenho, assim como auferir a maior fatia do total de ordens de compra emitidas para um componente.

\section{Metodologia}

O método de pesquisa foi o estudo de caso múltiplo. Esta abordagem é adequada quando as condições e limites do objeto ou fenômeno em estudo não estão claramente definidos ou quando a questão de pesquisa 
versa sobre uma exploração ou construção da teoria (YIN, 1994). Para o estudo de caso múltiplo, foram selecionadas cinco empresas compradoras e quatro tipos de produtos de alto valor agregado, perfazendo vinte combinações.

Voss, Tsikriktsis e Frohlich (2002) enfatizam a importância de se ter variáveis de controle em estudos de caso. Assim sendo, e considerando eventuais diferenças entre empresas e produtos selecionados, bem como objetivando viabilizar comparações metodologicamente respaldadas entre as organizações estudadas, os pesquisadores definiram critérios para a escolha de empresas compradoras, fornecedores e componentes. A definição surgiu em sessões de grupos focados com participação de pesquisadores, consultores praticantes e praticantes de empresas.

A seleção das empresas compradoras considerou sua presença global e a existência de um setor de engenharia de compras, ou similar, para apoiar a seleção de fornecedores e produtos. A seleção dos componentes considerou que devem ser itens padronizados e de alto valor agregado. Os itens devem ser utilizados por uma ampla gama de empresas, tanto como subsistemas para construção de produtos finais como para manutenção de ativos produtivos. Os fornecedores devem ter plantas produtivas em diversas partes do mundo. Além disso, as empresas devem ter representantes ou distribuidores que atendam regularmente às empresas clientes a serem analisadas. Dez empresas compradoras foram convidadas. Cinco aceitaram participar da pesquisa. Por solicitação delas, suas marcas comerciais não serão divulgadas, apenas seus setores de atividade, a saber: mineração, siderurgia, equipamentos e bebidas. Uma lista de vinte itens foi proposta às compradoras, que apontaram aqueles que atendiam às condições especificadas e eram adquiridos regularmente. $\mathrm{O}$ cruzamento das informações resultou em uma lista de quatro componentes ou subsistemas, a saber: rolamentos, sistemas hidráulicos, componentes pneumáticos e sistemas eletrônicos. Grupos de gestores de compras foram formados nas empresas para responder às perguntas dos pesquisadores.

Um protocolo de estudo de caso considerando as dimensões de valor em análise (produto, serviço e suprimento) foi elaborado. Os entrevistadores questionaram qual o mais importante critério de compra utilizado pela empresa em itens premium. Depois, perguntaram que outros critérios eram utilizados após o critério mais importante ter sido atendido. Posteriormente, foi questionado acerca da influência desses valores em níveis de preço e fração de ordem de cada componente. O protocolo permitiu outros métodos de coleta, incluindo, além das entrevistas, observação direta e análise documental. No que se refere à análise documental, os pesquisadores tiveram acesso aos registros codificados de compra de itens premium em um período de três anos. Observações diretas acerca das informações auferidas nas entrevistas e na análise documental compuseram as demais evidências consideradas pelos investigadores. Uma vez que alguns itens não estavam sob a tutela de um mesmo gestor de compras, fez-se necessária a execução de algumas entrevistas adicionais. As entrevistas duraram entre 30 e 90 minutos.

\section{Resultados}

As informações coletadas ao longo das entrevistas, as observações feitas pelos pesquisadores e os resultados da análise documental são apresentadas no Quadro 1.

Nas duas primeiras colunas têm-se as empresas compradoras e tipos de componente. Na terceira e quarta colunas são apresentados os valores prioritários e secundários considerados pelas compradoras em relação aos produtos. Conforme definido pelos pesquisadores, valores prioritários são mandatórios para a aquisição do produto. Os valores secundários são considerados pelos compradores após a garantia de existência dos prioritários. Todas as menções puderam ser associadas aos valores extraídos da literatura: Produto (Desempenho do Produto em Campo ou Especificação do Fabricante do Equipamento onde o item é utilizado), Serviço (Suporte Técnico) e Suprimento Confiável (por parte do fornecedor). A quinta coluna apresenta o adicional de preço que a empresa tem pagado a um produto premium em comparação a um similar sem os diferenciais listados. A última coluna informa a fração do lote de compra destinado ao fornecedor desse tipo de produto em comparação com os produtos de menor valor agregado.

As informações do Quadro 1 foram reorganizadas no Quadro 2 a fim de viabilizar uma análise qualitativa conforme a proposta por Miles e Huberman (1994). Nas linhas tem-se as compradoras; nas colunas, os produtos; e nas células, os valores prioritários, seguidos dos secundários. O Quadro 2 indica que as empresas compradoras analisadas definem seus fornecedores prioritariamente, e quase que exclusivamente, com base na especificação do fabricante e/ou no desempenho do produto (com exceção dos subsistemas pneumáticos e hidráulicos da Siderúrgica 2). Estes critérios podem ser associados ao valor produto.

Conforme apurado, algumas empresas baseiam sua decisão de compra apenas no desempenho do produto em campo. A preferência pelos valores associados ao produto pode ainda decorrer da mandatória especificação definida pelos fabricantes dos equipamentos (para itens de manutenção de máquinas já instaladas na empresa). A presença 
Quadro 1. Informações auferidas.

\begin{tabular}{|lccccc|}
\hline \multicolumn{1}{|c}{ Comprador } & Produto & $\begin{array}{c}\text { Valores } \\
\text { prioritários }\end{array}$ & $\begin{array}{c}\text { Valores } \\
\text { secundários }\end{array}$ & $\begin{array}{c}\text { Adicional de } \\
\text { preço (\%) }\end{array}$ & $\begin{array}{c}\text { Fração do } \\
\text { lote (\%) }\end{array}$ \\
\hline Fabricante & Rolamentos & Desempenho & Desempenho & 5 & 10 \\
de bebidas & Eletrônicos & Desempenho & Suprimento confiável & 10 & 30 \\
& Hidráulicos & Desempenho & Suprimento confiável & 4 & 10 \\
Fabricante & Pneumáticos & Desempenho & Suprimento confiável & 4 & 10 \\
de equipamentos & Rolamentos & Desempenho & Suporte técnico & 5 & 20 \\
& Eletrônicos & Desempenho & Suporte técnico & 5 & 10 \\
& Hidráulicos & Especificação & Suprimento confiável & 5 & 20 \\
Empresa de & Pneumáticos & Especificação & Suprimento confiável & 5 & 10 \\
mineração & Rolamentos & Especificação & Suprimento confiável & 10 & 20 \\
& Eletrônicos & Especificação & Desempenho & 8 & 10 \\
& Hidráulicos & Especificação & Desempenho & 5 & 10 \\
Empresa & Pneumáticos & Especificação & Desempenho & 5 & 10 \\
siderúrgica 1 & Rolamentos & Desempenho & Desempenho & 3 & 10 \\
& Eletrônicos & Desempenho & Desempenho & 3 & 30 \\
& Hidráulicos & Desempenho & Suprimento confiável & 3 & 30 \\
Empresa & Pneumáticos & Desempenho & Suprimento confiável & 3 & 20 \\
siderúrgica 2 & Rolamentos & Desempenho & Suporte técnico & 5 & 10 \\
& Eletrônicos & Especificação & Desempenho & 8 & 10 \\
& Hidráulicos & Suprimento confiável & Suporte técnico & 5 & 10 \\
& Pneumáticos & Especificação & Suporte técnico & 5 & 5 \\
\hline
\end{tabular}

Quadro 2. Valores demandados.

\begin{tabular}{|lcccc|}
\hline & Rolamentos & Eletrônicos & Hidráulicos & Pneumáticos \\
\hline Bebidas & Desempenho/ & Desempenho/ & Desempenho/ & Desempenho/ \\
& Desempenho & Suprimento & Suprimento & Suprimento \\
Equipamentos & Desempenho/ & Desempenho/ & Especificação/ & Especificação/ \\
& Suporte técnico & Suporte técnico & Suprimento & Suprimento \\
Mineração & Especificação/ & Especificação/ & Especificação/ & Especificação/ \\
& Suprimento & Desempenho & Desempenho & Desempenho \\
Siderúrgica 1 & Desempenho/ & Desempenho/ & Desempenho/ & Desempenho/ \\
& Desempenho & Desempenho & Suprimento & Suprimento \\
Siderúrgica 2 & Desempenho/ & Especificação/ & Suprimento/ & Especificação/ \\
& Suporte técnico & Desempenho & Suporte técnico & Suporte técnico \\
\hline
\end{tabular}

global dos fornecedores dos componentes analisados muitas vezes equipara-os no nível do valor do produto, condição essa que leva os clientes industriais a definir suas compras com base nos valores secundários, mais especificamente os valores associados ao suporte técnico e ao suprimento confiável. Assim sendo, a opção de fornecimento pode também ser decidida pela combinação de valores prioritários e secundários.

A Figura 1 apresenta a influência de cada par de valores demandados (prioritários + secundários) sobre os preços e fração do lote de compra. Uma análise de correlação entre as duas últimas colunas do Quadro 1 apontou um coeficiente de determinação $R^{2}=0,0047$, o que indica ausência de correlação entre as grandezas. Conclui-se que o adicional de preço obtido e a fração de lote não guardam entre si relações de influência, só podendo ser analisados caso a caso. Não se chegou a uma expressão que os relacionasse de modo significativo.

\subsection{Influência do valor produto sobre preço e fração do lote}

A Figura 2 foi gerada com base nos dados extraídos do Quadro 1 e apresenta a influência exclusiva do valor produto sobre os preços e a fração de ordem de cada componente em estudo junto ao grupo de clientes (casos em que o valor produto foi mencionado tanto como valor prioritário como secundário). A influência deste tipo de valor varia entre $3 \%$ e $8 \%$ no preço. Itens hidráulicos e pneumáticos parecem possuir menos 




Figura 1. Influência da associação de valores.

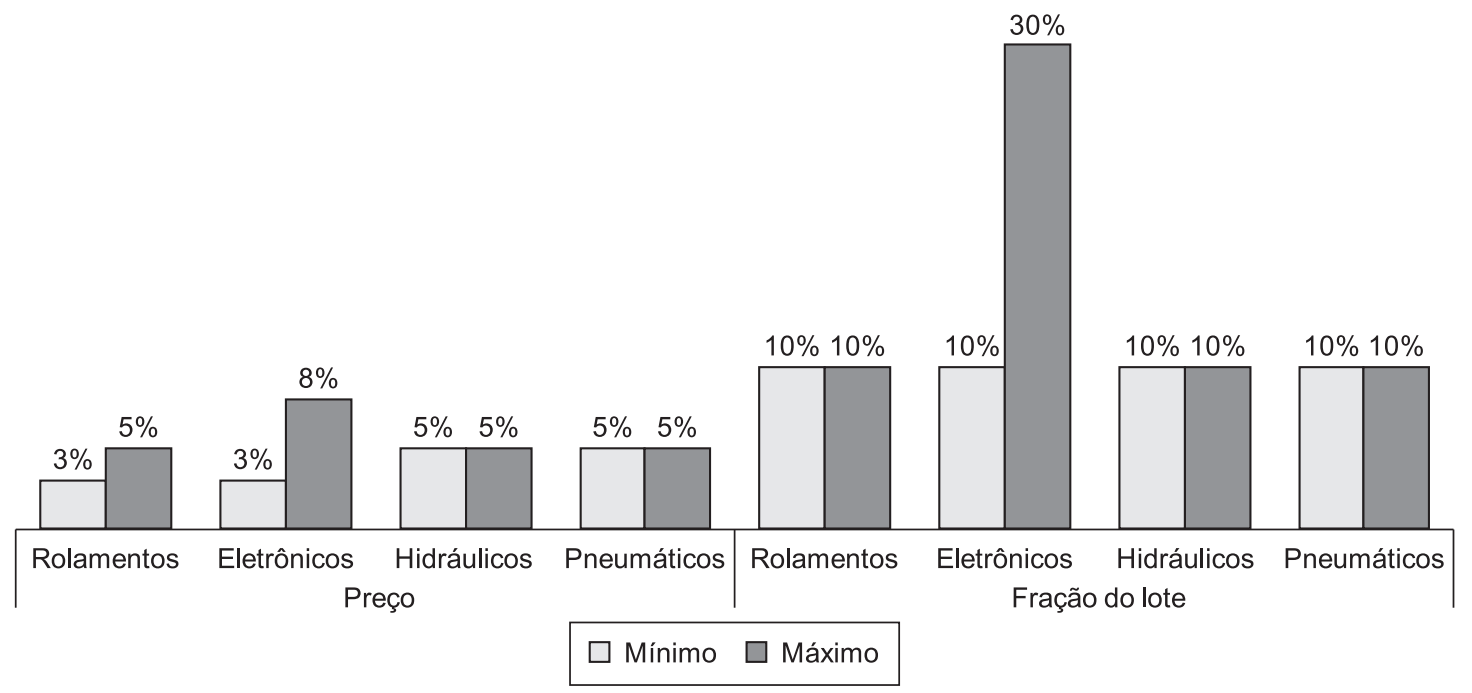

Figura 2. Influência do valor produto.

elasticidade em preço que os eletrônicos (3-8\%). Quanto à fração de pedido, varia de 10\% a 30\% nos eletrônicos, sendo constante e igual a $10 \%$ nos demais. A compensação total (preço + fração da ordem) dos fornecedores de eletrônicos é maior do que a verificada em rolamentos, hidráulicos e pneumáticos. Cumpre destacar que, com exceção da siderúrgica 1 (30\% na fração do lote de compra - vide Quadro 1), todas as demais compradoras apresentam políticas de compras similares em considerando o valor produto.

\subsection{Influência do par produto - serviço}

Conforme apresentado no Quadro 1, o valor Serviço nunca foi mencionado como prioritário. O par produto (prioritário) e serviço (secundário) foi também o menos citado como capaz de influenciar preços pagos e fração do pedido de um dado item. Os entrevistados declararam ainda que o suporte técnico é a única modalidade de serviço capaz de justificar algum adicional de compensação ao fornecedor neste tipo de item, haja vista que o tratamento adequado das reclamações dos clientes e outros aspectos descritos na literatura não justificariam tal compensação.

A Figura 3 apresenta graficamente as informações referentes ao par produto - serviço. Apenas a Siderúrgica 2 e o fabricante de equipamentos consideram que o referido valor justifica a concessão de alguma compensação adicional aos fornecedores. $\mathrm{O}$ adicional de preço praticado nesses casos é fixo $(5 \%)$ 
e a fração do lote varia de $5 \%$ (pneumáticos junto à siderúrgica 2) a 20\% (rolamentos junto à indústria de equipamentos). Itens eletrônicos e pneumáticos correspondem a $10 \%$ da fração do lote de compra de um dado componente.

Considerando que a compensação total engloba os elementos preço e fração do pedido de compra, é possível concluir que a empresa produtora de equipamentos recompensa mais generosamente seus fornecedores de itens de maior valor agregado que a Siderúrgica 2. Questionados sobre tal compensação os entrevistados do fabricante de equipamentos declararam que a necessidade de suporte quando do projeto de novos produtos justifica a diferença.

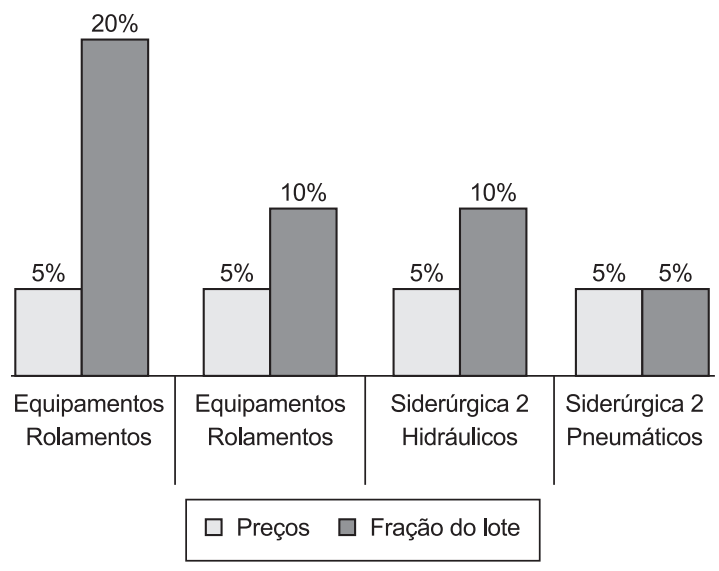

Figura 3. Influência do par produto - serviços.

\subsection{Influência do par produto - suprimento}

Conforme Quadro 1, o par produto - suprimento confiável foi o mais demandado pelos clientes industriais analisados, eis que foi mencionado em oito dos vinte casos. A influência do par na compensação financeira de fornecedores surge na Figura 4. Com exceção dos rolamentos adquiridos pela mineradora e dos componentes eletrônicos adquiridos pelo fabricante de bebidas, a compensação em preço oscila entre 3\% e $5 \%$ e em fração de pedido entre $10 \%$ e $30 \%$. Em síntese, fornecedores são compensados mais por fração maior dos pedidos do que por preços maiores.

Questionados, os gestores de suprimentos entrevistados declararam que este tipo de compensação se baseia nos seguintes pressupostos: (i) na fábrica de equipamentos, essa estratégia objetiva reduzir os níveis de estoques de peças destinadas à montagem de seus produtos; e (ii) nas empresas que adquirem o item para a manutenção, essa estratégia objetiva estimular os fornecedores a manter estoques de itens prontos de forma a garantir o rápido suprimento em caso de quebras inesperadas nos equipamentos utilizados na produção.

\section{Discussão e novas pesquisas}

$\mathrm{O}$ valor produto foi o mais demandado pelos compradores, tendo sido mencionado como valor prioritário em 19 das 20 combinações entre empresa e tipo de produto. Em outras 7 combinações estudadas, o valor produto foi mencionado simultaneamente

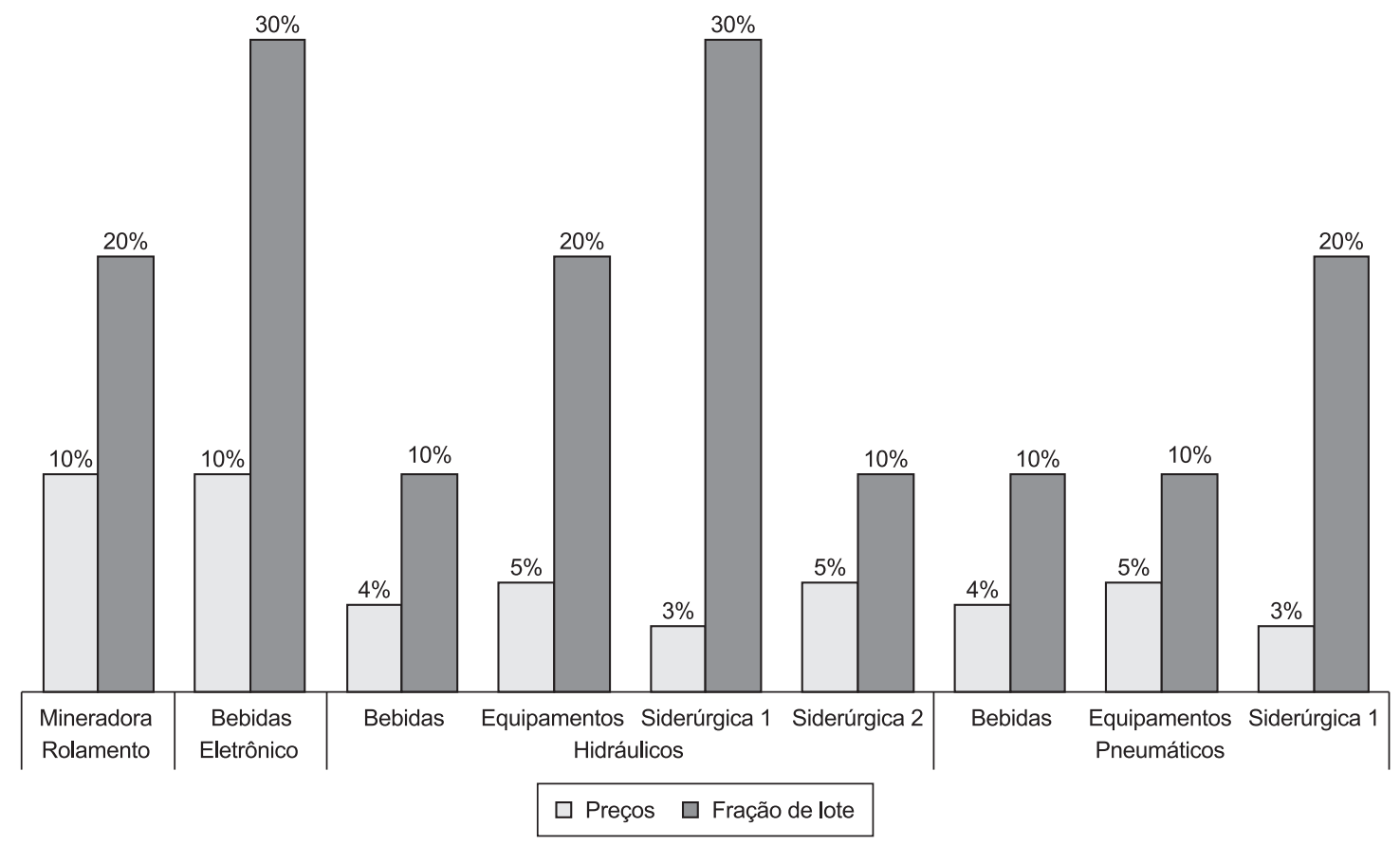

Figura 4. Influência do par produto - suprimento. 
como valor prioritário e secundário para a definição da opção de compra (nesses casos não houve menções aos demais valores descritos na teoria). A associação entre os valores produto + suprimento foi mencionada em 8 combinações, enquanto o par produto + serviços foi mencionado em 3 das combinações entre empresas e produtos. Esses achados sugerem uma possível uniformidade de critérios, o que fornece suporte à proposição P1, bem como se alinha a conclusões já obtidas por Dickson (1966), Lehmann e O'Shaughnessy (1974), Dempsey (1978), Evans (1981), Lehmann e O'Shaughnessy (1982), Sharma e Achabal (1982), Jackson (1985), Matthyssens e Faes (1985), Giunipero e Brewer (1993), Wilson (1994), Bennion e Redmond (1994) e Oliver (1997).

Em relação a esta parte do estudo, podem-se formular algumas questões para pesquisas futuras: Por que alguns fornecedores globais dos componentes estudados não investem no atendimento dos valores nos quais possuem menor desempenho com o objetivo de aumentar sua penetração nos mercados analisados? Como um fornecedor de equipamentos poderia quantificar a viabilidade e a atratividade de prover dado valor aos seus clientes? Que outros elementos, além dos preços e da fração de pedidos devem ser considerados?

Quanto ao valor produto, a possibilidade de influenciar preços (entre 3\% e $8 \%$ ) e a fração do lote de compra (entre $10 \%$ e $30 \%$ ), quantificou a percepção deste valor. As citadas faixas de variação não suportaram a proposição $\mathrm{P} 2$, tanto em preços, quanto em fração de pedidos. As informações auferidas também sugerem que a influência do valor produto varia conforme o tipo de componente, o que confirma e quantifica as diferentes percepções de valor propostas por Bharadwaj (2004). Essa conclusão desvela questões para pesquisa futura: Como os compradores definem os limites aceitáveis em termos de preço e fração de ordem para um dado valor? Que elementos induzem uma empresa a compensar seus fornecedores com base em preços, em frações de pedido ou ambos? Por que alguns produtos têm uma compensação total maior que outros? Como avaliar a conveniência de se investir no desenvolvimento de um produto superior ao da concorrência, considerando-se os limites de preço e a fração de pedido identificados?

Resultou claro que a Siderúrgica 1 tem uma política de compras diferente das demais (inclusive da siderúrgica 2, sua concorrente), recompensando fornecedores de itens premium com o menor adicional de preços identificado e a maior fração de pedidos. As referências consultadas não fazem menção aos motivos que induzem às diferenças detectadas, fato que sugere a necessidade de realização de futuros estudos destinados a analisar o referido tópico em profundidade.
Do ponto de vista dos fornecedores, a análise sugeriu a necessidade de desenvolvimento de produtos com os diferenciais demandados pelos clientes. Em paralelo, os fornecedores devem desenvolver políticas de aproximação com os clientes, especialmente os fabricantes de equipamentos, haja vista que muitos engenheiros de manutenção definem os itens a serem adquiridos exclusivamente com base nas especificações do fabricante do equipamento.

Quanto ao valor Serviço, a pesquisa identificou que este não é tido como prioritário pelos compradores industriais deste tipo de item, mas sim como um valor secundário (5 menções entre as 20 combinações de empresa e produto investigadas). Essa constatação amplia os achados de Ulaga e Eggert (2006) e Jackson, Neidell e Lunsford (1995) ao sugerir a existência de uma hierarquia de atratividade entre os valores. Quanto ao par produto - serviços, identificou-se que ele permite aos fornecedores praticar preços até 5\% superiores aos concorrentes. A fração de pedidos oscila entre 5\% e 20\%. Essas informações recomendam a rejeição total da proposição P3 para preços e a rejeição parcial para a fração de pedidos. As informações coletadas também identificaram que o suporte técnico é o tipo de serviço que efetivamente agrega valor nessas transações. A pesquisa à literatura não identificou menção a esses aspectos. Ademais, as faixas de variação identificadas sugerem que o par produto - serviços não é demandado uniformemente pelas empresas. Esta diferença pode ser decorrente da combinação de alguns elementos descritos na literatura, dentre os quais se citem: nível de serviço (VARGO; LUSCH, 2004), diferenças entre os compradores (GIUNIPERO; BREWER, 1993; BENNION; REDMOND, 1994; OLIVER, 1997) ou tipos de produtos (BHARADWAJ, 2004; LINDGREEN; WYNSTRA, 2005).

A maioria das empresas compradoras adquire os componentes em foco para manutenção dos ativos produtivos, um tipo de demanda que não requer muito suporte técnico. No entanto, a única empresa que os adquire para construção de produtos finais (indústria de equipamentos) declarou valorizar, e muito, esse tipo de valor. Essas conclusões sugerem que a demanda por serviços depende da utilização que o cliente irá fazer do componente industrial. Esta parte dos achados sugere algumas questões para pesquisa futura: Que outros elementos podem determinar a variação da compensação praticada pelos compradores industriais investigados em se tratando de serviços de suporte técnico? Como explicar a diferença entre a compensação concedida aos fornecedores de rolamentos pela indústria de equipamentos e a compensação concedida aos eletrônicos pela empresa siderúrgica, dado que esses produtos, embora diferentes entre si, são tidos como de alto valor agregado pelo mercado industrial? 
Quanto ao par produto - suprimento, autores analisaram a influência do fornecimento confiável na satisfação dos clientes (CHAKRABORTY; SRIVASTAVA; MARSHALL, 2007; HSIEH; CHIU; HSU, 2008). Contudo, esses achados de pesquisa deixaram margem à seguinte questão: Qual compensação os compradores estão dispostos a oferecer aos fornecedores que proveem tal associação de valores? Esta pesquisa detectou que suprimento confiável é o valor secundário mais considerado pelos compradores (8 menções entre as 20 combinações de empresa e produto investigadas). Aos fornecedores que oferecem este valor, os clientes industriais aceitam pagar um adicional de preço de $3 \%$ a $5 \%$ e reservam de $10 \%$ a $30 \%$ do lote de compra para esses fornecedores, mesmo que esses provedores pratiquem preços maiores. Essa constatação sugere a rejeição da proposição P4 para preço e parcialmente para a fração de pedidos.

A análise das compensações totais (preço + fração de pedido) sugere que a maioria dos clientes estudados compensa seus fornecedores com um pequeno aumento nos preços e uma mais generosa compensação na fração de pedidos. Até onde foi revisada a literatura, nenhum comentário acerca dessa abordagem de compensação de fornecedores foi encontrado.

Cumpre ainda destacar a ausência de padrões claros para a definição das compensações totais oferecidas às empresas fornecedoras de um mesmo setor de atividade (vide o caso dos componentes hidráulicos nas siderúrgicas 1 e 2). Com efeito, essa ausência de padrões também ocorre dentro de uma mesma empresa, como demonstram os itens hidráulicos e pneumáticos adquiridos pela indústria de equipamentos, ou os itens hidráulicos, pneumáticos e eletrônicos comprados para a manutenção da indústria de alimentos (Figura 4). Uma vez que a menção aos padrões de compensação dos fornecedores não foi encontrada na literatura, identifica-se aqui mais uma possibilidade de investigação futura com vistas à determinação dos elementos que induzem tal postura.

Essas conclusões desvelam mais perguntas para futuras pesquisas: Por que as empresas preferem compensar seus fornecedores com base na fração de pedidos do que no preço? Por que os fornecedores de destaque em nível internacional que foram preteridos pelos compradores globais estudados, quando da definição dos fornecedores de produtos premium, não investiram em seus sistemas logísticos com o objetivo de conquistar os pedidos dos compradores analisados neste estudo? Os problemas de suprimento que impedem a satisfação dos compradores analisados têm sua origem nos sistemas produtivos ou nos sistemas logísticos dos fornecedores preteridos?

\section{Conclusões}

Esta pesquisa buscou contribuir para um melhor entendimento da influência da associação dos valores usualmente considerados pelos compradores industriais sobre os preços e a fração do pedido de compra destinada a um dado fornecedor. Foram verificados três elementos geradores de valor para o comprador extraídos da literatura, a saber: produto, serviço e suprimento confiável.

Inicialmente, foi constatado que a quase totalidade das compras de componentes industriais se define com base nos valores de produto (valor prioritário), sendo que os valores serviço e suprimento, em geral, são considerados valores secundários, e sua influência sobre a opção de compra somente se dá quando o valor prioritário (produto) já foi atendido pelo fornecedor. Isso denota que, em caso de empate, a opção de fornecimento será pela associação entre o valor prioritário e o secundário. Nas transações em que o cliente define sua opção com base apenas nos valores de produto, as compensações dos fornecedores em preço oscilam entre $3 \%$ e $8 \%$, sendo que a fração de pedido é fixa em 10\% (com exceção dos eletrônicos em uma empresa que é recompensada com 30\%). Esses achados de pesquisa quantificam, em nível de preço e fração de ordem, o valor criado pelos produtos superiores, identificado por Matthyssens, Vandenbempt e Berghman (2006). A variação dos valores de produto entre as várias categorias de produto propostas por Bharadwaj (2004) foram confirmadas e quantificadas. Nenhuma menção ao valor dessas compensações foi encontrada na literatura revisada.

Quanto ao valor serviços, esta pesquisa identificou que o suporte técnico é a única variante demandada pelos compradores industriais estudados, conforme proposto por Ulaga e Eggert (2006) e Jackson, Neidell e Lunsford (1995). Considerado um valor secundário, o serviço permite aos seus provedores auferir um sobrepreço de 5\% e uma fração de pedidos entre 5\% e 20\%. Entretanto, as associações do valor serviços com outros não atrai todos os compradores igualmente, o que sugere que as abordagens universais de oferta de valor nesta área não são bem vistas pelos clientes industriais. Novas pesquisas são necessárias para a ampliação do entendimento científico de temas já propostos na literatura, dentre os quais: adequação dos serviços (VARGO; LUSCH, 2004); diferenças nas demandas dos compradores (BENNION; REDMOND, 1994; GIUNIPERO; BREWER, 1993; JACKSON, 1985; OLIVER, 1997; SHARMA; ACHABAL, 1982); e a relação serviços - produtos (BHARADWAJ, 2004).

Quanto ao valor suprimento, esta pesquisa identificou que os fornecedores podem cobrar preços de $3 \%$ a $5 \%$ maiores, recebendo uma fração de pedidos entre $10 \%$ e $20 \%$. Essas conclusões quantificam a importância do valor em foco postulada por outros autores (CHAKRABORTY; SRIVASTAVA; MARSHALL, 2007; HSIEH; CHIU; HSU, 2007). Cumpre destacar que a compensação total oferecida 
aos fornecedores para este valor usualmente consiste de um pequeno aumento em nível de preços e uma maior fatia em nível de ordens de compra. A referida estratégia de compensação, até onde se pesquisou na literatura, ainda não havia sido descrita em nível científico, especialmente em termos quantitativos, o que sugere a execução de novos estudos com vistas à ampliação do entendimento científico do tema.

As múltiplas questões de pesquisa advindas deste estudo de caso serão organizadas e investigadas em uma futura pesquisa survey.

\section{Limitações}

A pesquisa considerou apenas a visão dos compradores de grandes organizações industriais e de um pequeno grupo de componentes, fornecidos por empresas de atuação global para clientes de presença internacional. Com efeito, essas definições constituem importantes limitações. Assim sendo, as atuais conclusões não podem ser generalizadas. Contudo, indicam a necessidade de novos estudos que investiguem outros produtos industriais, incorporem a visão dos vendedores, assim como façam uso de métodos quantitativos que permitam a generalização das conclusões. Outra limitação advém do fato de que não se questionou a importância estratégica dos componentes analisados, o que fez com que todos os componentes fossem considerados de igual importância para os compradores.

\section{Agradecimentos}

Os autores agradecem aos revisores por suas valiosas colaborações para a melhoria do texto final deste artigo.

\section{Referências}

ANDERSON, C.; NARUS, J. A. Business market management. Upper Saddle River: Prentice Hall, 2004.

ANDERSON, J. C.; THOMSON, J. B. L.; WYNSTRA, F. Combining price and value to make purchase decisions in business markets. International Journal of Research in Marketing, v. 17, n. 4, p. 307-329, 2000.

ANDREASEN, A. R.; BEST, A. Consumers complain: does business respond? Harvard Business Review, v. 55, n. 4, p. 90-101, 1977.

BADEN-FULLER, C.; STOPFORD, J. M. Rejuvenating the mature business. Boston: Harvard Business School Press, 1994.

BALLOU, R. Gerenciamento da cadeira de suprimentos: logística empresarial. 5. ed. Porto Alegre: Bookman, 2006.

BANTING, P. M. Customer service in industrial marketing: a competitive study. European Journal of Marketing, v. 10, n. 3, p. 36-45, 1984.

BENNION, M. L.; REDMOND, W. H. Modeling customer response in an industrial commodity market. Industrial
Marketing Management, v. 23, n. 5, p. 383-392, 1994.

BHARADWAJ, N. Investigating the decision criteria used in electronic components procurement. Industrial Marketing Management, v. 33, n. 4, p. 317-323, 2004.

BOLTON, W.; DREW, J. H. A multistage model of customers' assessment of service quality and value. Journal of Consumer Research, v. 17, n. 4, p. 375-384, 1991.

BUZZELL, R. D.; GALE, B. T. The PIMS principles. New York: The Free Press, 1987.

CANNON, J. P.; HOMBURG, C. Buyer-supplier relationships and customer firm costs. Journal of Marketing, v. 65, n. 1, p. 29-43, 2001.

CARR, L. P.; ITTNER, C. D. Measuring the cost of ownership. Journal of Cost Management, p. 42-51, 1992.

CHAKRABORTY, G.; SRIVASTAVA, P.; MARSHALL, F. Are drivers of customer satisfaction different for buyers/users from different functional areas? Journal of Business \& Industrial Marketing, v. 22, n. 1, p. 20-28, 2007.

CHUSIL, M.; DOWNS, S. When value helps: the pims letter on business strategy. Cambridge: The Strategic Planning Institute, 1979.

DAVIES, A. Integrated solutions: the changing business of systems integration. In PRENCIPE, A. (Ed.). The business of systems integration. New York: Oxford, 2003. p. 333-368.

DEMPSEY, W. A. Vendor selection and the buying process. Industrial Marketing Management, v. 7 n. 4, p. 257-267, 1978.

DICKSON, G. W. An analysis of supplier selection systems and decisions. Journal of Purchasing, v. 2, n. 1, p. 5-17, 1966.

EISENHARDT, K. Building theories from case study research. Academy of Management Review, v. 14, n. 4, p. 532-550, 1989.

ELLRAM, L. M. Activity-based costing and total cost of ownership: a critical linkage. Journal of Cost Management, v.8, n.4, p. 22-30, 1995.

ERIKSSON, K.; LÖFMARCK-VAGHULT, A. Customer retention, purchasing behavior and relationship substance in professional services. Industrial Marketing Management, v. 29, n. 4, p. 363-372, 2000.

EVANS, R. H. Product involvement and industrial buying. Journal of Purchasing and Materials Management, v. 18, n. 2, p. 23-28, 1982.

FORNELL, C. A national satisfaction barometer: the swedish experience. Journal of Marketing, v. 56, n. 1, p. 1-21, 1992.

GEBAUER H.; FRIEDLI, T. Behavioral implications of the transition from products to services. Journal of Business \& Industrial Marketing, v. 20, n. 2, p. 70-78, 2005.

GIUNIPERO, L. C.; BREWER, D. J. Performance-based evaluation systems under total quality management. International Journal of Purchasing and Materials Management, v. 29, n. 1, p. 35-42, 1993.

HINTERHUBER, A. Towards value-based pricing : an integrative framework for decision making. Industrial 
Marketing Management, v. 33, n. 8, p. 765-778, 2004.

HSIEH, Y., CHIU, H.; HSU, Y. Supplier market orientation and accommodation of the customer in different relationship phases. Industrial Marketing Management, v. 37, n. 4, p. 380-393, 2008.

JACKSON, B. B. Winning and keeping industrial customers. New York: D.C. Heath and Company, 1993.

JACKSON, R. W., NEIDELL, L. A.; LUNSFORD, D. A. An empirical investigation of the differences in goods and services as perceived by organizational buyers. Industrial Marketing Management, v. 24, n. 2, p. 99-108, 1995.

KENT, J. L.; MENTZER, J. T. The effect of investment in interorganizational information technology in a retail suprimento chain. Journal of Business Logistics, v. 24, n. 2, p. 155-175, 2003.

KHALIFA, A. S. Customer value: a review of recent literature and an integrative configuration. Management Decision, v. 42, n. 5, p. 645-666, 2004.

LEHMANN, D. R.; O'SHAUGHNESSY, J. Difference in attribute importance for different industrial products. Journal of Marketing, v. 38, n. 1, p. 36-42, 1974.

LEHMANN, D.R.; O'SHAUGHNESSY, J. Decision criteria used in buying different categories of products. Journal of Purchasing and Materials Management, v. 18, n. 1, p. 9-14, 1982.

LINDGREEN, A.; WYNSTRA, F. Value in business markets: what do we know? where are we going? Industrial Marketing Management, v. 34, n. 7, p. 732-748, 2005.

MATTHYSSENS, P.; FAES, W. OEM buying process for new components: purchasing and marketing implications. Industrial Marketing Management, v. 14 n. 3, p. 145-157, 1985.

MATTHYSSENS, P.; VANDENBEMPT, K. Moving from basic offerings to value-added solutions: strategies, barriers and alignment. Industrial Marketing Management, v. 37, n. 3, p. 316-328, 2008.

MATTHYSSENS, P.; VANDENBEMPT, K.; BERGHMAN, L. Value innovation in business markets: breaking the industry recipe. Industrial Marketing Management, v. 35, n. 6, p. 751-761, 2006.

MILES, M.; HUBERMAN, A. Qualitative data analysis: an expanded sourcebook. 2. ed. Beverly Hills: Sage, 1994.

NOORDEWIER, T. G.; JOHN, G.; NEVIN, J. R. Performance outcomes of purchasing arrangements in industrial buyer-vendor relationships. Journal of Marketing, v. 54, n. 4, p. 80-93, 1990.

OLIVA, R.; KALLENBERG, R. Managing the transition from products to services. international. Journal of
Service Industry Management, v. 14, n. 2, p. 160-172, 2003.

OLIVER, R. L. Satisfaction: a behavioral perspective. New York: McGraw-Hill, 1997.

PAIVA, E.; CARVALHO Jr, L.; FENSTERSEIFER, J. Estratégia de produção e de operações. Porto Alegre: Bookman, 2004.

PAYNE, A.; HOLT, S. Diagnosing customer value: Integrating the value process and relationship marketing. British Journal of Management, v. 12, n. 2, p. 159-182, 2001.

REICHHELD, F. F. The loyalty effect: the hidden force behind growth, profits, and lasting value. Boston: Harvard Business School Press, 1996.

RUST, R. T.; ZAHORIK, A. Customer satisfaction, customer retention and market share. Journal of Retailing, v. 69, n. 2, p. 193-216, 1993.

SCHEUING, E. E. Creating customers for life. Portland: Productivity Press, 1995.

SHARMA, S.; ACHABAL, D. D. STEMCOM: an analytical model for marketing control. Journal of Marketing, v. 46, n. 2, p. 104-113, 1982.

ULAGA, W. Customer value in business markets: an agenda for inquiry. Industrial Marketing Management, v. 30, n. 4, p. 315-319. 2001.

ULAGA, W.; EGGERT, A. Value-based differentiation in business relationships: gaining and sustaining key supplier status. Journal of Marketing, v. 70, n. 1, p. 119-136, 2006.

VARGO, S. L.; LUSCH, R. F. Evolving to a new dominant logic for marketing. Journal of Marketing, v. 68, n. 1, p. 1-17, 2004.

VOSS, C.; TSIKRIKTSIS, N.; FROHLICH, M. Case research in operations management. International Journal of Operations \& Production Management, v. 22, n. 2, p. 195-219, 2002.

WILSON, E. L. The relative importance of supplier selection criteria: a review and update. International Journal of Purchasing and Materials Management, v. 30, n. 3, p. 35-41, 1994.

WINDAHL, C.; LAKEMOND, N. Developing integrated solutions: the importance of relationships within the network. Industrial Marketing Management, v. 35, n. 7, p. 806-818, 2006.

WOUTERS, M.; ANDERSON, J. C.; WYNSTRA, F. The adoption of total cost of ownership for sourcing decisions: a structural equations analysis. Accounting, Organizations and Society, v. 30, n. 2, p. 167-191, 2005.

YIN, R. Case-study research: design and methods. 2. ed Beverly Hills: Sage, 1994.

ZEITHAML, V. Service quality, profitability, and the economic worth of customers: what we know and what we need to learn. Journal of the Academy of Marketing Science, v. 28, n. 1, p. 67- 85, 2000. 